\title{
Spatio-temporal patterns of the Red-footed Falcon's hunting behavior during the nestling period suggest ad hoc conservation policies
}

\author{
Marco Gustin and Alessandro Ferrarini ${ }^{*}$ (D)
}

\begin{abstract}
The Red-footed Falcon (Falco vespertinus) is a species of high international conservation interest. We analyzed its hunting behavior at the two largest colonies in Italy during the nestling period. Using accurate data-loggers, we tracked three adult Red-footed Falcons in June and July, 2019 and collected 4703 GPS points. We detected clear patterns of hovering and perching activity (HPA) in both time and space. HPA occupied one-third of the Red-footed Falcons' day, and showed two peaks just after sunrise (between 35 and $40 \%$ of the monitoring time) and just before sunset (50-60\%) in both June and July, and minimum (20-30\%) at night and during the hottest time interval (10:00 a.m.-4:00 p.m.). Almost $40 \%$ of HPA occurred within $50 \mathrm{~m}$ from nests. Our findings, although preliminary, have important implications for the conservation of these two colonies that are located within two Natura 2000 sites. The detected spatio-temporal patterns of Red-footed Falcons' hunting behavior suggests the creation of two nested protection belts: the inner one is a narrow belt (up to $50 \mathrm{~m}$ from the two rows of trees that host the two colonies) with integral conservation, and hopefully increase the alfalfa crops and fallow land, and the outer belt $(50 \mathrm{~m}-2 \mathrm{~km})$ with optimized agricultural activities.
\end{abstract}

Keywords: Biotelemetry, Falco vespertinus, Hovering, Italy, Natura 2000 site, Perching

\section{Correspondence}

The Red-footed Falcon (Falco vespertinus) is classified as near threatened in the IUCN Red List (BirdLife International 2018), and as globally threatened Species of European Conservation Concern (SPEC; BirdLife International 2017). This facultative colonial breeder dwells in open rural environments with a predominance of extensive cultivation and pasture, and presence of rows of trees (BirdLife International 2004). The recent degradation of its foraging habitats was primarily caused by the conversion of grasslands to agricultural fields and the intensification of agriculture (Palatitz et al. 2015a, 2018; BirdLife International 2018).

*Correspondence: sgtpm@libero.it; alessandro.ferrarini@lipu.it Conservation Department, BirdLife, LIPU (Lega Italiana Protezione Uccelli), Via Udine 3, 43100 Parma, Italy
The Red-footed Falcon is a short-grass specialist that can feed upon different food resources, like Amphibia, Insecta, Mammalia and Reptilia (Purger 1998). Redfooted Falcons have three distinct hunting strategies: perching, hovering and aerial insect capture (Palatitz et al. 2009, 2015b). Perch hunting is performed from elevated observation posts, mostly power lines, pylons and telephone cables because they gave the Red-footed Falcons an unrestricted view straight beneath and an unlimited choice of stances. The birds sit on these vantage points scanning the ground, and wait until a prey item is near enough to launch a successful attack. Instead, active hunting requires the bird catching large insects in flight, or hovering with fast wing beats (whose frequency is negatively correlated with bird's body mass) above a spot and then making strikes on the prey (Tobalske 2010). Generally, hovering costs more 
than perch-hunting from an energetic viewpoint, but yields more per unit time (Rudolph 1982).

Using accurate GPS data-loggers, we analyzed the Red-footed Falcon's population in province of Parma in 2019 (Italy; Fig. 1). This geographical area hosts $>90 \%$ of the Red-footed Falcons breeding in Italy (Brichetti and Fracasso 2020) in two colonies situated within two Natura 2000 sites (SPA IT4020018 Prati e ripristini ambientali di Frescarolo e San Boseto; SAC-SPA IT4020017 Aree delle risorgive di Viarolo, Bacini di Torrile, Fascia golenale del Po). It is a rural environment (Additional file 1: Fig. S1) with isolated rows of Black Poplar (Populus nigra) and Oak (Quercus robur) trees used by Redfooted Falcons for nesting and roosting, and extensive cultivation with Scattered Alfalfa (Medicago sativa) crops. A recent conservation project (Calabrese et al. 2020) has compensated for the lack of nesting sites in the study area using artificial nest boxes placed in rows of trees considered to be optimal for these birds (Additional file 1: Fig. S2). In this study, we aimed to: (1) analyze the Red-footed Falcon's hovering and perching activity in this largest Red-footed Falcon's population in Italy during the nestling period, (2) detect potential temporal and spatial patterns, and (3) advance tailored conservation strategies based on our findings.
Three Red-footed Falcons, belonging to three different nests, were surveyed from June 16th to September 15th, 2019 (Additional file 2: Table S1). We chose only adult Red-footed Falcons in good health conditions. Birds were captured near their nests using decoy birds and mist nets. We used TechnoSmart RadioTag-14 data-loggers, that supplied information about date, time, latitude, longitude, flight height and instantaneous flight speed (FS; $\mathrm{m} / \mathrm{s}$ ). The RadioTag-14 system makes use of a wireless data download when the base station antenna is within $400 \mathrm{~m}$ from the tracked individuals. Data acquisition occurred every 15 min during two time periods: day (6:00 a.m.-9:00 p.m. local time) and night (9:00 p.m.-6:00 a.m. local time). Through intensive field surveys, we located the nests and roosts used by the tracked individuals. Using digital orthophotos, we also mapped $>800 \mathrm{~km}$ of rows of trees (Additional file 1: Fig. S3) present in the study area to detect potential opportunistic (i.e., small and rarely used) roosting sites used by the Red-footed Falcons during the nestling period.

GPS data were imported into GIS along with (1) boundaries of the province of Parma, (2) digital orthophotos, (3) locations of nests, roosts and rows of trees. For each GPS point, we calculated the distance from the individual's nest (DN; in meters) and from the nearest roosting site/row of trees (DR; in meters). GPS points

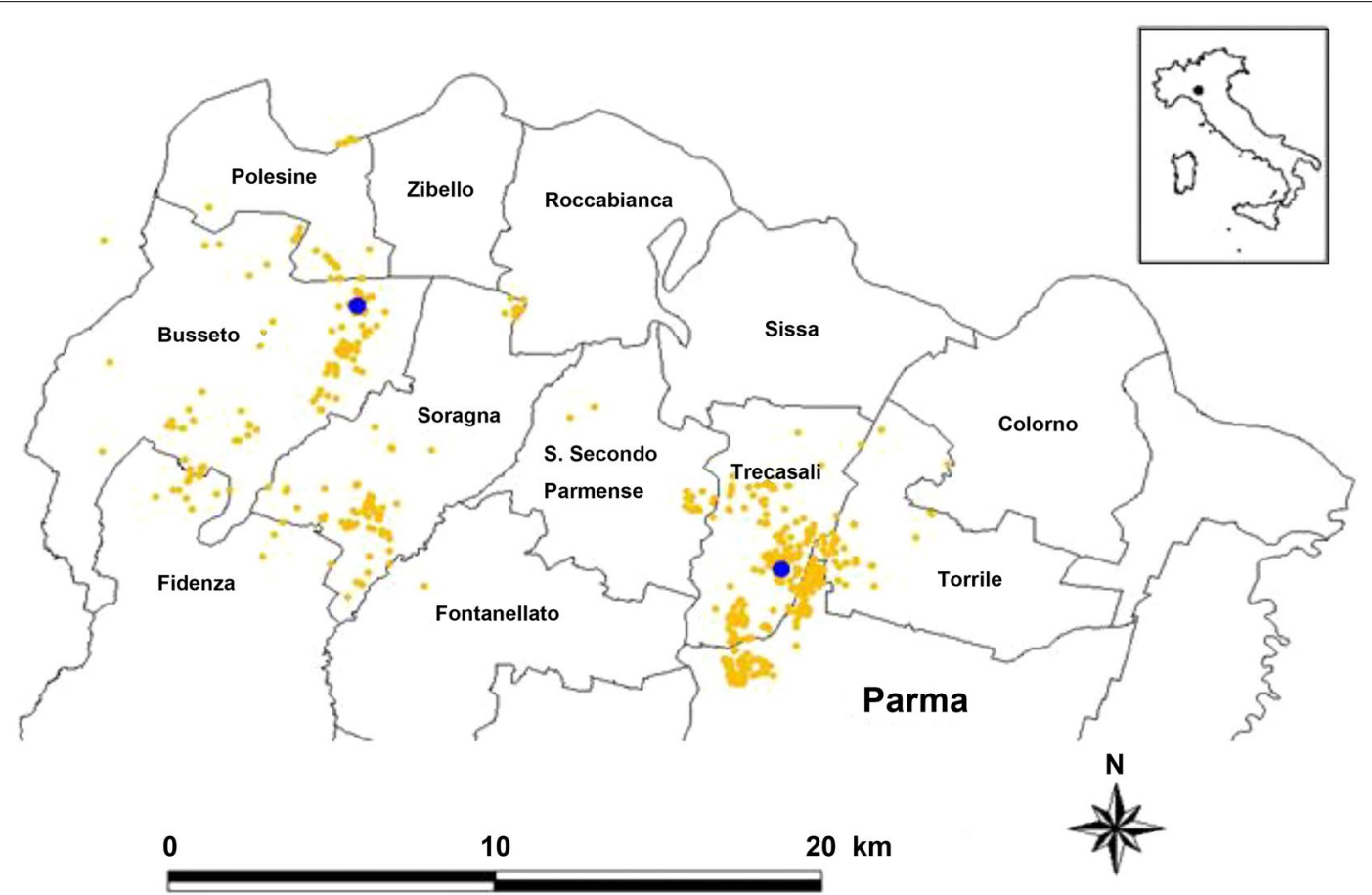

Fig. 1 Study area (province of Parma, Italy) and 1567 GPS points (yellow dots) showing the hovering/perching activity of three Red-footed Falcons surveyed from June 16th to July 22th, 2019. Municipalities are outlined in black. The blue dots indicate the two Red-footed Falcons' colonies present in the study area (top left: colony $\mathbf{a}$, one individual tracked; bottom right: colony $\mathbf{b}$, two individuals tracked) 
were classified as hovering/perching activity (HPA) if, and only if, $\mathrm{FS}=0, \mathrm{DN}>1 \mathrm{~m}$ and $\mathrm{DR}>1 \mathrm{~m}$, i.e., if the bird was motionless outside the nest and roosting sites/row of trees. We chose a 1-m threshold because, through digital orthophotos, we estimated the radius of the Black Poplar and Oak tree canopies used for nesting and roosting to be about equal to that size. We used only GPS points collected from June 16th to July 22th, 2019 when all birds were tracked (i.e., we discarded GPS data available for the individual 5003 from July 23th to September 15th, 2019).
HPA occupied $33.32 \%$ of the monitoring time (1567 GPS points out of 4703), almost equally distributed between June (32.25\%; 447/1386 GPS points) and July (33.77\%; $1120 / 3317$ points). HPA occupied $34.18 \%$ of the time (1279 GPS points out of 3742 ) by day, and $29.97 \%$ at night (288/961 GPS points).

On an hourly basis (Fig. 2; Additional file 2: Table S2), HPA showed two peaks just after sunrise (between 30 and $70 \%$ of the monitoring time) and just before sunset (40-60\%). During the hottest time interval (10:00

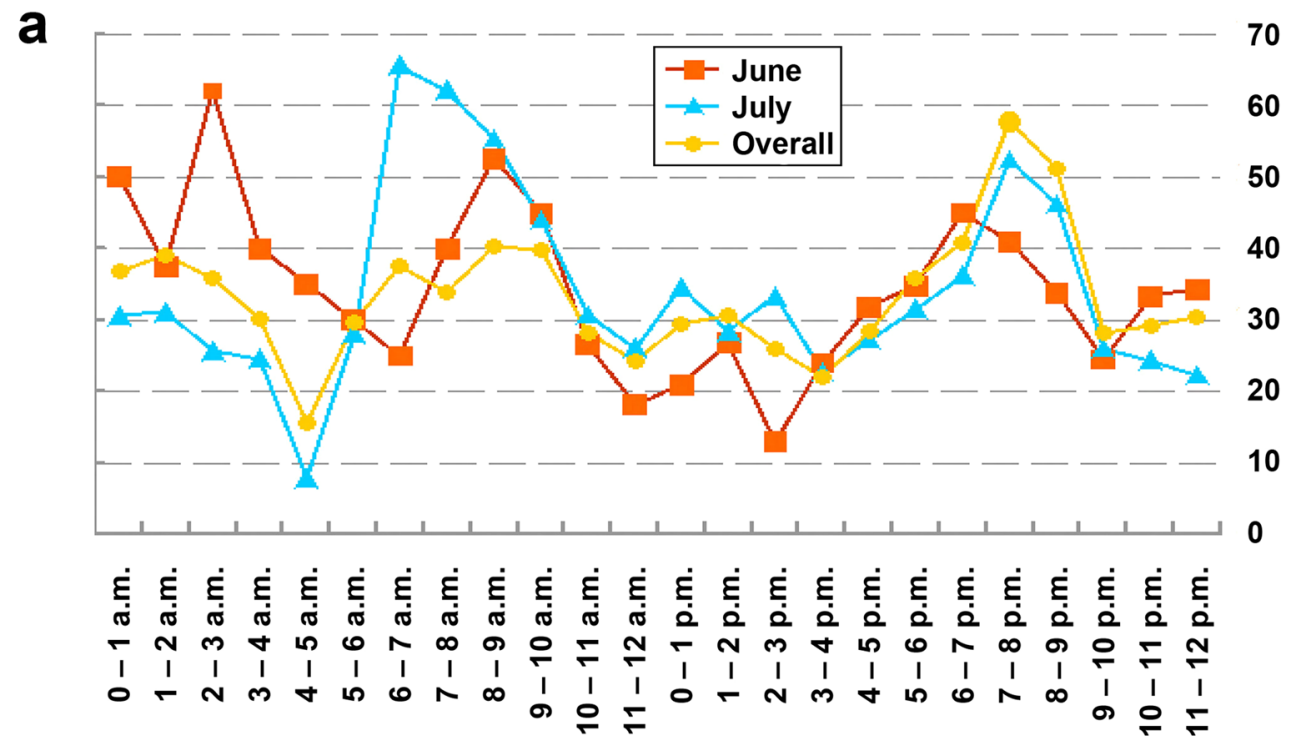

b

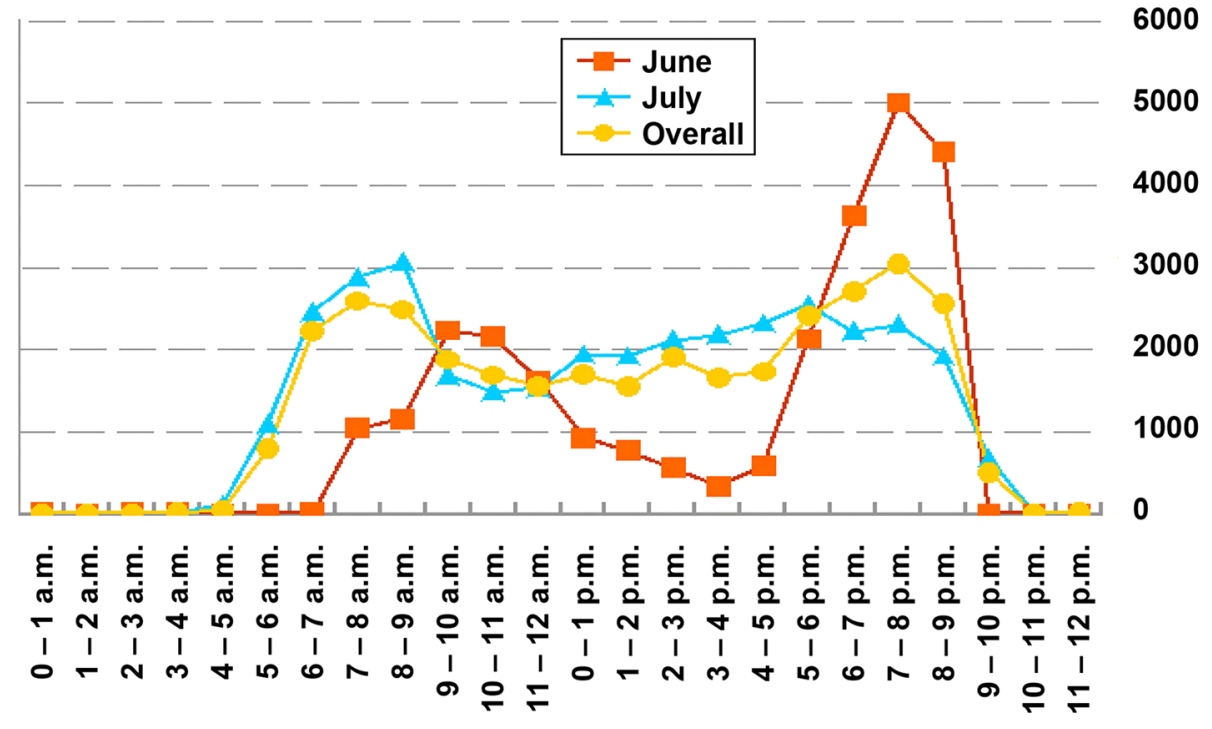

Fig. 2 a Proportion (in \%) of time spent in hovering/perching activity by the tracked Red-footed Falcons (with data from all individuals pooled) in different time intervals (local time). b Average distance from nests (in meters) of the hovering/perching activity (with data from all individuals pooled) in different time intervals (local time) 
a.m. $-4: 00$ p.m.) and at night, HPA was lower (20-40\%). Only minor differences emerged between June and July, i.e., an elevated HPA in June during 2:00-3:00 a.m. (61.90\%; 13 of out 21 GPS points), a 2 -h shift in the peak after sunrise (6:00-7:00 a.m. in July and 8:00-9:00 a.m. in June) and a 1-h shift before sunset (6:00-7:00 p.m. in June and 7:00-8:00 p.m. in July).

On average, HPA occurred at $1690 \mathrm{~m}$ ( \pm 3191 SD) from nests in June, and $1827 \mathrm{~m}( \pm 2263 \mathrm{SD})$ in July. On an hourly basis, a clear spatial pattern emerged (Fig. 2b; Additional file 2: Table S2), with two peaks just after sunrise (average DN between 2 and $3 \mathrm{~km}$ ) and before sunset $(2-5 \mathrm{~km})$. June and July showed similar twopeak patterns, except for a one-hour shift in the first peak after sunrise (9:00-10:00 a.m. in June and 8:009:00 a.m. in July), lower distances from nest in June during the hottest time interval (10:00 a.m.-4:00 p.m.) and higher distance from nest (up to $5 \mathrm{~km}$ ) in June before sunset.

HPA showed a bimodal distribution (Fig. 3; Additional file 2: Table S3) as $39.95 \%$ of this activity that was carried out within $50 \mathrm{~m}$ from nests (Additional file 1: Fig. S4), and another $31.08 \%$ at distances $>2 \mathrm{~km}$. These two peaks approximately corresponded to the nocturnal (first peak) and diurnal (second peak) HPA activity. At night, the distance from nest of HPA was minimum (average $\mathrm{DN}=143 \mathrm{~m} \pm 574 \mathrm{SD} ; 21.67 \mathrm{~m} \pm 15.58 \mathrm{SD}$ in June; $198.80 \mathrm{~m} \pm 686.87 \mathrm{SD}$ in July) while it was $>2 \mathrm{~km}$ in the daytime (average $\mathrm{DN}=2159 \mathrm{~m} \pm 2687 \mathrm{SD} ; 2110 \mathrm{~m} \pm 3446$ $\mathrm{SD}$ in June; $2177 \mathrm{~m} \pm 2330 \mathrm{SD}$ in July).
We were not able to distinguish between hovering and perch hunting because power lines, pylons and telephone cables are common in the study area, but not easily detectable on the digital orthophotos at 1:10,000 scale available for this study. For this reason, we could not distinguish between birds laying upon these vantage points, or instead motionless in air while hovering. Our field surveys, limited to the daytime, were not sufficient to unravel this question because we observed both active and passive hunting. We knew from the literature (Tobalske 2001, 2010) that hovering is a frequent but also brief (usually $<1 \mathrm{~min}$ ) activity, while perching usually takes several minutes. Therefore, with short GPS fixes (e.g. $30 \mathrm{~s}$ ) we could have distinguished between a persistent behavior (perching) and a discontinuous (hovering) one. We instead chose 15-min GPS fixes because short GPS fixes determine a fast consumption of the GPS battery with long blind intervals before battery recharge. However, both hovering and perching are part of the hunting behavior, thus we considered them as complementary activities.

HPA resulted an important part of Red-footed Falcons' behavior during the nestling period, in fact it occupied one-third of the day with minor differences between June and July. When split on an hourly basis and in classes of distance from nests, HPA showed clear spatio-temporal patterns. The Red-footed Falcons' hunting behavior was active during the whole day, although with two peaks just after sunrise and before sunset. At night HPA was carried out in the close surroundings of the nests, instead in the

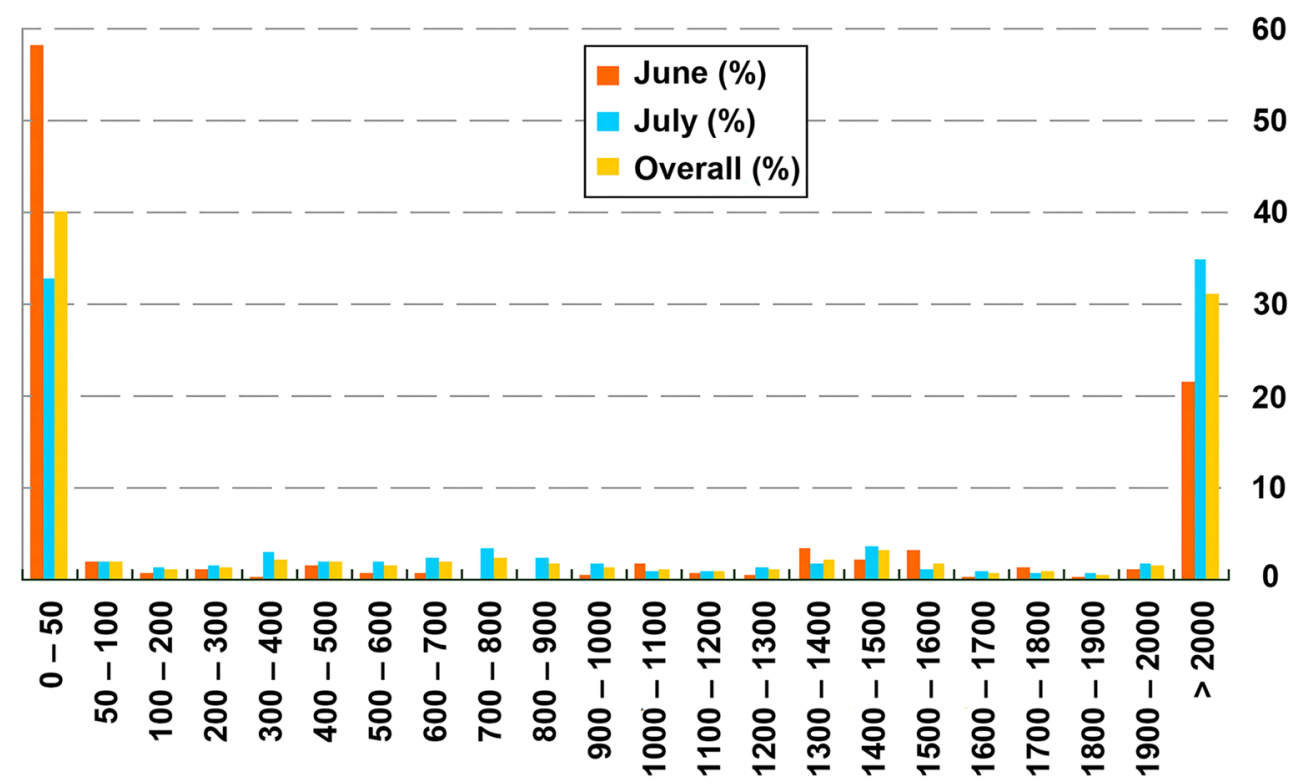

Fig. 3 Proportions (in \%) of the Red-footed Falcons' hovering/perching activity (with data from all individuals pooled) in each class of distance (in meters) from nests. Key to reading: in June, almost 60\% of the hovering/perching activity was carried out within $50 \mathrm{~m}$ from nests 
daytime the Red-footed Falcons preferred long-distance flights towards more suitable foraging patches several km away from nests.

It is plausible that the nocturnal light conditions forced the Red-footed Falcons to hunt very close to their nests. In fact, flight activity is much more comfortable by day when the light intensity increases up to six orders of magnitude (Hart 2001), therefore long flights toward more suitable foraging patches resulted unfit at night. In both colonies, nests are surrounded by a rural environment with little optimal foraging patches (alfalfa crops and fallow land) scattered among large arable fields with low prey abundance. This landscape composition is not optimal for foraging, but in a trade-off between optimal foraging (benefit) and difficulties in flight activities due to low visibility (cost), the Red-footed Falcons chose a short-range hunting strategy at night. As the light levels increased around sunrise, the Red-footed Falcons started a wide-range HPA toward the most suitable foraging patches (alfalfa crops and fallow land) present in the study area. This first peak of HPA took several hours after which, in the middle of the day, the Red-footed Falcons preferred to reduce HPA probably because the elevated temperature (generally $>30-35{ }^{\circ} \mathrm{C}$ in June and July) discouraged hunting activities, and also because they were temporarily satiated after the first peak of HPA. The Redfooted Falcons then employed the late hours of daylight before sunset to intensify HPA again (second peak) with long-distance flights towards more suitable foraging patches several $\mathrm{km}$ away from nests.

Our findings suggest several conservation measures for this species in the study area. The importance of the foraging habitat within $50 \mathrm{~m}$ from nests emerged clearly. This portion of the study area is vital for the Red-footed Falcons at night when they are used to hunt very close to their nests. In both colonies, this area presents little optimal foraging patches (alfalfa crops and fallow land) scattered among large arable fields with low prey abundance. The integral preservation of the optimal foraging patches present in the close surroundings of the nests, and also incentives to farmers through the Rural Development Programme to increase alfalfa crops and fallow land in place of maize and soy crops (whose extent increased fast in the recent years; Calabrese et al. 2020) are decisive for the preservation of this species in the study area. Given the limited extent of this protection area (i.e., $\pi \times(50 \mathrm{~m})^{2}=7850$ $\mathrm{m}^{2}$ ), such management policies seem highly feasible. In addition, our findings showed that Red-footed Falcons minimized their hunting activity within $2 \mathrm{~km}$ from nests during the daytime. This suggests that, when Redfooted Falcons are not constrained by visibility, they prefer to avoid partially-unsuitable foraging habitats and hunt where optimal foraging patches are larger and more frequent. As the area comprised between $50 \mathrm{~m}$ and $2 \mathrm{~km}$ from nests is rather large ( 1256 ha), the integral preservation of optimal foraging patches and incentives to increment them in place of maize and soy crops seem rather unfeasible. However, a less integral conservation strategy is possible. Some management techniques (delayed mowing, increased use of pesticides, and low percentages of grazed pastures) can result in severe shortage of foraging patches for the Red-footed Falcons (Palatitz et al. 2015b, 2018). The modification of these unfit agricultural practices through an open dialogue and cooperation with local stakeholders should be possible if supported by incentives from the Rural Development Programme, and could result in the increase of suitable foraging patches for Red-footed Falcons' mid-range hunting in this portion of their local home range. Although less likely to obtain, the improvement of the management practices could also integrate the reduction in agricultural activities in correspondence of the detected peaks of hunting activity.

Overall, the spatio-temporal patterns of Red-footed Falcons' hunting behavior suggested the creation of two nested protection belts in the study area, the inner one is a narrow belt (up to $50 \mathrm{~m}$ from the two rows of trees that host the two colonies) with integral conservation, and hopefully increase the alfalfa crops and fallow land, the outer belt $(50 \mathrm{~m}-2 \mathrm{~km})$ with optimized agricultural activities. Because the two colonies considered in this study are located within two Natura 2000 sites, these proposals should be considered relevant in their conservation measures and management plans.

\section{Supplementary Information}

The online version contains supplementary material available at https://doi. org/10.1186/s40657-021-00243-y.

Additional file 1: Figure S1. Two details of the study area (northern portion of the province of Parma, Italy). Figure S2. The rows of Black Poplar (Populus nigra) and Oak (Quercus robur) trees that host the Red-footed Falcons' colonies A and B. Figure S3. The rows of trees present in the study area. Figure S4. Hunting/perching activity occurred in the close surroundings of the rows of trees where nests are located.

Additional file 2: Table S1. Description of the tracked Red-footed Falcons. Table S2. Temporal pattern of the Red-footed Falcons' hovering/ perching activity. Table S3. Spatial pattern of the Red-footed Falcons' hunting activity in June, July and during the whole monitoring period.

\section{Acknowledgments}

We are grateful to LIPU-UK that funded this study. We thank Giuseppe Giglio for assistance during GPS logger deployment. We thank the Editor and anonymous reviewers for their useful remarks that improved this manuscript. 


\section{Authors' contributions}

AF, MG conceived the study; MG carried out the field work; AF carried out the GIS and modelling work; AF, MG drafted the earlier version of the manuscript. All authors read and approved the final manuscript.

\section{Funding}

This work was supported by LIPU-UK.

\section{Availability of data and materials}

The datasets used in the present study are available from the corresponding author on reasonable request.

\section{Ethics approval and consent to participate}

Our research adheres to local guidelines and appropriate ethical approval and licences were obtained.

\section{Consent for publication}

Not applicable.

\section{Competing interests}

The authors declare that they have no competing interests.

Received: 4 October 2020 Accepted: 19 January 2021

Published online: 08 February 2021

\section{References}

BirdLife International. Birds in Europe: population estimates, trends and conservation status. Cambridge: BirdLife International; 2004.

BirdLife International. European birds of conservation concern: populations, trends and national responsibilities. Cambridge: BirdLife International; 2017.
BirdLife International. Falco vespertinus. In: The IUCN red list of threatened species. 2018; e.T22696432A131939286. https://doi.org/10.2305/IUCN. UK.2018-2.RLTS.T22696432A131939286.en.

Brichetti P, Fracasso G. The birds of Italy. Latina: Edizioni Belvedere Press; 2020 Calabrese L, Mucciolo A, Zanichelli A, Gustin M. Effects of nest boxes on the most important population of red-footed falcon Falco vespertinus in Italy. Conserv Evid. 2020:20:35-9.

Hart NS. Variations in cone photoreceptor abundance and the visual ecology of birds. J Comp Physiol A. 2001;187:685-97.

Palatitz P, Fehérvári P, Solt S, Barov B. European species action plan for the Redfooted Falcon Falco vespertinus Linnaeus, 1766. BirdLife International for the European Commission; 2009.

Palatitz P, Fehérvári P, Solt S, Horváth É. Breeding population trends and premigration roost site survey of the Red-footed Falcon in Hungary. Ornis Hungarica. 2015;23:77-93.

Palatitz P, Solt S, Horváth É, Kotymán L. Hunting efficiency of Red-footed Falcons in different habitats. Ornis Hungarica. 2015;23:32-47.

Palatitz P, Solt S, Fehérvári P. The blue vesper: ecology and conservation of the red-footed Falcon. Budapest: MME; 2018.

Purger JJ. Diet of Red-footed Falcon Falco vespertinus nestlings from hatching to fledging. Ornis Fennica. 1998;75:185-91.

Rudolph SG. Foraging strategies of American Kestrels during breeding. Ecology. 1982;63:1268-76.

Tobalske BW. Morphology, velocity, and intermittent flight in birds. Amer Zool. 2001:41:177-87.

Tobalske BW. Hovering and intermittent flight in birds. Bioinspir Biomim. 2010;5:045004.
Ready to submit your research? Choose BMC and benefit from:

- fast, convenient online submission

- thorough peer review by experienced researchers in your field

- rapid publication on acceptance

- support for research data, including large and complex data types

- gold Open Access which fosters wider collaboration and increased citations

- maximum visibility for your research: over 100M website views per year

At BMC, research is always in progress.

Learn more biomedcentral.com/submissions 